\title{
A ESCULTURA EM ESPAÇO PÚBLICO NA UNIVERSIDADE ESTADUAL DE CAMPINAS: SUA RESTAURAÇÃO E PRESERVAÇÃO COMO PATRIMÔNIO CULTURAL HISTÓRICO E ARTÍSTICO
}

\author{
Vivian Palma Braga dos Santos \\ Instituto de Artes, Departamentos de Artes Plásticas, Unicamp
}

Contíguo ao pensamento cultivado nos anos 80 - à produção de peças tridimensionais em espaços públicos, com o objetivo de valorizá-los como espaços de convivência - surgi também, uma ocupação semelhante da arte pública nos campus das universidades. No entanto, o número de espaços universitários no Brasil que cultivam um acervo nessa linha ainda é escasso, destacando-se por sua preservação e conservação a Universidade Estadual de São Paulo, através do trabalho da professora Maria Cecília França Lourenço em "Bens e Imóveis tombados ou em processo de tombamento da USP" (1999).

Apesar de pouco divulgado, a Unicamp também possui um acervo escultórico em suas dependências. Em agosto de 2006, através da pesquisa de Iniciação Científica intitulada "A escultura em espaço público na Universidade Estadual de Campinas: sua restauração e preservação como Patrimônio Cultural Histórico e Artístico", se iniciou um estudo realizando um levantamento dessas obras, sua história de criação e instalação, como primeiro passo para compreender a relevância desta produção dentro do contexto próprio de seu surgimento, para uma futura catalogação e captação de recursos para restauro como produto do trabalho. Considerando sempre, a importância dessas obras como parte da história do campus, compiladores de transformações ocorridas através dos anos, como aspecto compositor inefável da história da arte nessa instituição cultural.

A falta de informação com respeito a esses trabalhos, de forma geral, estabeleceu-se como desencadeadora deste projeto. Localizada no complexo da área médica da Unicamp, no local onde funcionava o Departamento de Medicina Legal, há uma escultura do professor Gastão Manoel Henrique. Esta feita de concreto, encontra-se deteriorada e tem suas ferragens expostas. Tais condições tornaram-se perigosas à comunidade que percorre o local. A faculdade de Ciências Médicas (FCM) solicitou providências à prefeitura do campus para que o "entulho" fosse retirado; foi feito um levantamento do custo de remoção da escultura, porém, por sorte, antes de removê-la, a Unicamp pediu um parecer sobre o assunto para o Instituto de Artes. O Departamento de Artes Plásticas então 
reagiu imediatamente, formatando um documento de posição firme contra a remoção da escultura com base na qualidade e importância do artista e da obra.

Este episódio chamou à consciência a necessidade de se promover um estudo capaz de resgatar a importância do patrimônio artístico da Universidade. O presente projeto nasceu como fruto desse desejo, configurando-se como uma primeira iniciativa nesse sentido. O objetivo do projeto é recuperar a história dessas obras, avaliar seu valor artístico e patrimonial e propor formas de divulgação e melhor comunicação entre a população do campus e o patrimônio artístico da Universidade Estadual de Campinas.

Após a aprovação do projeto de foi realizado um levantamento minucioso a respeito das obras dispostas no campus. Apesar de um número surpreendente de obras, a dificuldade de encontrar documentos a respeito desses trabalhos foi intensa. Um primeiro trabalho pioneiro nesse sentido foi desenvolvido pela artista Sylvia Furegatti como parte dos requisitos para a obtenção de créditos em uma disciplina cursada na pós-graduação que desenvolve junto à FAU-USP (FUREGATTTI, 2003). Os documentos compilados são, no geral, documentos de doação das esculturas, vídeos e arquivos pessoais dos artistas, bem como entrevistas com estes e funcionários do período em que as esculturas foram instaladas.

Tratam-se, no momento, de um total de 15 trabalhos, oriundos do Projeto Artes no Campus, do Programa de Artistas Residentes e ainda, obras adquiridas em regime de doação.

A primeira investida escultórica na Unicamp se dá em 1985. Parte de Suely Pinotti a proposta de ocupação dos espaços abertos do campus com obras criadas pelos artistas-professores do Instituto de Artes. Uma comissão formada por Carlos Vogt, Omar Marquese, Ubiratan D`Ambrosio e Almeida Prado selecionaram os seguintes trabalhos, realizados no período de 1985 a 1989: "A criança e o universo", de Suely Pinotti; "A cor na paisagem", de Noboru Ohnuma; "Monumento à Campinas", de Akiko Fujita; "Vegetais", de Berenice Toledo; "Mater", de Fúlvia Gonçalves; "Eixo paralelo ao da rotação da Terra", de Marco do Valle; uma escultura em concreto armado Sem título, de Gastão Manoel Henrique. Posteriormente, somou-se ao acervo os trabalhos dos artistas residentes Ricardo Basbaum e José Roberto Hofling - com os títulos de "O Olho"e "Peixe", respectivamente -, doações de dois trabalhos de Károly Pichler, um intitulado "Pássaro de fogo" e outro em ferro Sem Título; "Movimento do mar", 
de Osni Branco "Nouva Identitá", de Simon Benetton e, "Vida em expansão", uma criação coletiva de projeto de Silvia Matos.

Dentre essas, um total de quatro já destruídas: apenas uma com resíduos ainda no local e as outras três, que deixaram totalmente de existir.

Executados com patrocínio de empresas como a COSIPA, aos trabalhos iniciais foram pré-estabelecidos espaços de localização. Outros, que estiveram expostos em algumas Bienais ou, como "Movimentos do Mar", na Feira de Metalúrgica do Anhembi, foram dispostos nos locais mais apropriados.

Alguns, como o trabalho de Marco do Valle estabelece uma relação íntima com a comunidade universitária através de sua estrutura já confeccionada e o significado que comporta. Diferente de "Monumento à Campinas", realizado pela professora Akiko Fujita, que hoje reside no Japão, que exerce essa relação no próprio aspecto "artesanal" do trabalho.

Akiko Fujita realiza esculturas em argila há mais de 40 anos. As formas abstratas de seu trabalho derivam de sua compreensão da figura humana e dialogam com o ambiente físico circundante através de concepções de "abrigo". Seu trabalho pode ser dividido em três etapas: com estudantes, artistas e todo tipo de pessoas, Akiko modela um alicerce labiríntico e, sobre esses, cones esburacados. Depois, realiza a queima a céu aberto, onde a obra se torna o próprio forno e, por último, realiza uma série de eventos ao redor da obra pronta. Para Akiko a idéia é fazer do Monumento um Movimento de Arte. A obra é um presente a terra.

\footnotetext{
"Estou sobre a terra, que envolve inúmeros acontecimentos que eu tenho visto, bem como toda história da existência humana. Sim, a terra contém tudo. Ela não tem fim e será sempre ativa. Todas as criaturas de originam dela e para ela retornam. Dessa forma eu desejo que minha existência tenha suas raízes no chão para poder expressar minha própria vida. Essa é minha razão dos meus trabalhos sobre a terra; o único caminho a provar minha existência é através dessa ação criadora. Como todas as coisas que são finitas, meus trabalhos de argila voltarão para a terra. Mas é sobre a terra que desejo produzir meus trabalhos, que podem existir como habitações e como parques."
}

Mas de onde vem à questão do abrigo?

\footnotetext{
"Duas cenas permanecem vivas em minha memória: uma é a imagem de imediatamente após a guerra, quando japoneses sem lar procuravam entre os escombros materiais com os quais pudessem construir um abrigo. A outra memória é em torno de um filme que mostrava cidades subterrâneas, construídas por nortes-vietnamitas para se protegerem dos bombardeios. A urgência, a energia, as pessoas e os espaços interligados por estas memórias, me inspiraram e me deram um certo poder de criação. Eu acho
} 
que somente os seres humanos são dotados de habilidades no uso da força criativa como um meio de proteger a vida ${ }^{p}$.

A artista plástica japonesa chega ao Brasil na década de 1980. Instala-se em Campinas e é contratada como professora de cerâmica pelo Departamento de Artes Plásticas da Unicamp. Segundo a Revista Veja "pressionada por amigos brasileiros, Akiko decidiu mudar de país em busca do espaço em que pudesse trabalhar em escala gigante" 2 .

Já em 1985 cria dois projetos para espaços abertos de universidades: o projeto Flores da Terra na $\mathrm{USP}^{3}$ e Monumento à Campinas na Unicamp. Infelizmente, o primeiro foi destruído pouco tempo depois de sua execução.

Akiko Fujita parabenizou a iniciativa da Universidade na ocupação de alguns lugares com trabalhos artísticos e, como todos os artistasprofessores que participaram do projeto Arte no Campus, também apresentou seu projeto; devido uma viagem programada anteriormente, ter tido de acelerar o processo, tendo o Monumento sido construído em apenas dois dias.

Localizado na praça atrás do Restaurante Universitário, Monumento à Campinas tratou-se se uma produção material onde a construção foi realizada somente com argila, dispensando o uso de qualquer estrutura interna. A escolha do local foi feita devido ao fácil acesso tanto da comunidade de Barão Geraldo, quanto da Unicamp. A execução da obra reuniu estudantes, habitantes da comunidade de Barão e profissionais da área que, com 10 toneladas de argila doadas pela Cerâmica Mingoni Ltda, moldaram uma estrutura de aproximadamente 6X3 metros. Todo o trabalho se deu em quatro períodos:

modelagem da base;

queima de baixa temperatura utilizando serragem;

modelagem das paredes do habitáculo;

queima de média temperatura, com lenha como combustível, folhas de zinco e telas como amarração: um grande forno.

1 Akiko Fujita. Texto da exposição "Esculturas em Argila", em 1988. Teatro Municipal de Piracicaba/SP.

2 Revista Veja, 15 de maio de 1985.

3 Com 200 metros quadrados e um metro e meio de altura, que foi localizado no centro da Praça do Relógio. 
Próximo ao fim da modelagem especificada no tópico 3, um grupo de crianças é trazido ao local. Akiko, mesmo com suas dificuldades com o português, explica a essas o que está acontecendo e, como poderão ajudar. As crianças agora fazem parte da obra; moldam, retocam. A queima da peça foi realizada ao ar livre. Enquanto desta, música, dança e apresentações teatrais eram apreciadas. O que a artista planejara se realizava: tratar o momento não somente como uma queima, mas como um verdadeiro ritual envolvendo às artes.

Infelizmente Akiko teve de retornar ao Japão e, com o passar dos anos a obra foi sofrendo inúmeros atos de vandalismo. Quando entrevistamos algumas pessoas que participaram do processo de estruturação do trabalho, elas afirmaram sua tristeza ao perceber que algo que fizeram parte foi destruído.

No ano de 1993, a Galeria de Arte da Unicamp efetivou seu pedido de restauro da obra, no entanto, como acontecido com outras esculturas no espaço público da Unicamp, não houve resposta.

A presente pesquisa, durante o período de sua vigência e através da documentação compilada questiona ainda, a posicionamento da Universidade em relação a este acervo, já que sua estruturação se tratou de uma iniciativa acadêmica. Questiona-se, ainda, até que ponto, a Universidade preserva, efetivamente, a sua história da arte exercendo sua função de instituição cultural. 


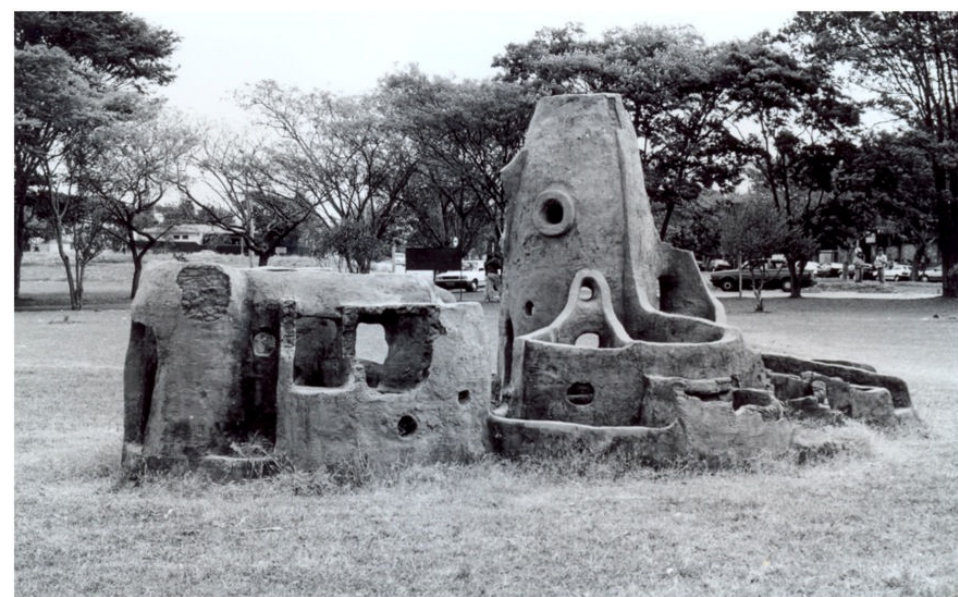

Monumento à Campinas, aproximadamente 1985.

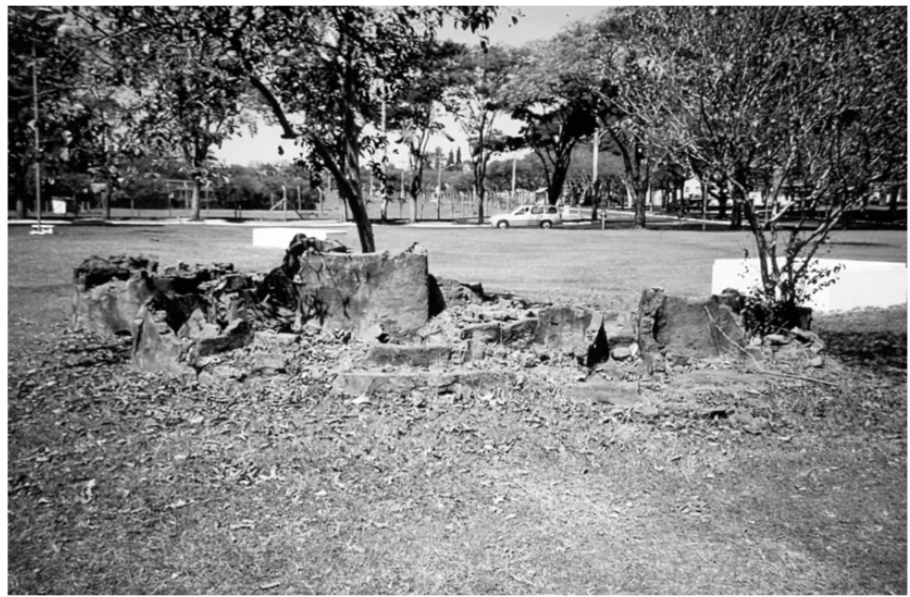

Monumento à Campinas atualmente:

Imagens:

Figura 1: fotografia de Letícia Achcar, cedida pelo arquivo da Galeria de Arte - Unicamp. Figura 2: fotografia de Vivian Palma, 2006. 


\section{Bibliografia}

ARANTES, Otília B. F. A Cidade do Pensamento Único: desmanchando consensos.Vozes. Petrópolis, 2000.

CAMPOS, Martha Machado. Arte na Cidade: da paisagem às dinâmicas urbanas. I Seminário ARTE E CIDADE, 2006.

CHOAY, Françoise. A Alegoria do Patrimônio; tradução de Luciano Machado. São Paulo: Editora Unesp, 2001.

FUJITA, Akiko. Memória. Universidade Estadual de Campinas. Instituto de Artes. Galeria de Arte Unicamp.

FUREGATTI, Sylvia. Arte no Campus - Aspectos da coleção de obras de arte pública da Universidade Estadual de Campinas. Trabalho final da disciplina Museus: Uma nova abordagem / FAU-USP. Doutorado. 2003.

GONÇALVES, Yacy-Ana Froner. Os Dominios da Memória - um estudo sobre a construção do pensamento preservacionista nos campi da Museologia, Arqueologia e Ciência da Conservação. Universidade de São Paulo, Faculdade de Filosofia, Letras e Ciências Humanas. Tese de doutorado sob orientação do Prof. Dr. Norberto Luiz Guarinello. São Paulo. 2001.

JAGUARIBE, Hélio. A Universidade e a Cultura Brasileira. in Revista do Patrimônio Histórico e Artístico. 21. Fundação Pró-Memória. Rio de Janeiro, 1986.

SÁNCHEZ, Fernanda. A reinvenção das cidades para um mercado mundial. São Paulo, 2001.

Jornais:

MONUMENTO para comemorar os 20 anos da Unicamp. Jornal Correio Popular, 02/06/83.

PAINÉIS e esculturas. Toque novo no campus. Jornal Diário do Povo, 16/08/1985.

AKIKO Fujita vai expor toneladas de cerâmica. Jornal Correio Popular, abril/1985.

Entrevista:

NEVES, Maria Lúcia. Entrevista (maio, 2007) Entrevistadora: Vivian Palma. Campinas: Galeria de Artes da Unicamp, 2007. 